\title{
Zhang Yimou's Shanghai Triad
}

\author{
By Yvonne Ng
}

Fall 1998 Issue of KINEMA

Just when it seemed as if every variety of the gangster genre had been played out, Mainland Chinese director Zhang Yimou sprang a pleasant surprise with his film Shanghai Triad (Yao a yao yao dao wai po qiao, 1995). The film is probably the last collaboration between the director and Gong Li, the leading actress in all his previous films $^{(1)}$ and his off-screen partner until the completion of this film.

Few gangster movies have been made in recent years that equal the film in its freshness, style, intelligence, sensual and lyrical beauty. However, in his interview with Zhang at the 1995 Cannes Film Festival, Nigel Andrews reported that Zhang's latest film had been indifferently received by critics who thought no more of it than "just a gangster film" and a mere waste of the director's talent ${ }^{(2)}$. Though under-appreciated as a gangster film, Shanghai Triad's merit has not been totally ignored. In 1995, it won the prize for Best Cinematography at the Cannes Film Festival, the Los Angeles Film Critics Circle, and the New York Film Critics Circle. It was also voted the Best Foreign Film at the American National Board of Review. Indeed, Shanghai Triad is anything but an ordinary gangster film.

Viewers who demand graphic violence as part of the gangster genre will find Shanghai Triad disappointing because this trait is significantly missing here. Those anticipating the brooding atmosphere of a film noir will be surprised by the vibrant glamour of a Shanghai cabaret in the first half of the film. Moreover, the hardened protagonist of a typical gangster film is replaced here by a naive fourteen-year-old boy called Shuisheng (Wang Xiaoxiao) from whose perspective we view much of the film.

Through these unconventional devices to the gangster genre, Zhang Yimou imbues the film with a unique and eloquent expression about expectation and reality, appearance and truth, the infinity of moral darkness and its corrosive reach. These eternal themes of the human condition are presented in a well-paced narrative revealing once more the director's gift for telling a story. Even more evident is Zhang's photographer's eye ${ }^{(3)}$ which has given Shanghai Triad, as in many of his other films, an impassioned, resonating beauty. His sense of mise-en-scène persuasively invokes the pre-WWII Shanghai.

In exploring the complexity of reality, a great film often invites different interpretations of its meanings and allusions. Shanghai Triad is such a film. Freely adapted from the novel Men Gui (Gang Law) by Li Xiao, Zhang's film has been described as a "parable about greed." ${ }^{(4)}$ The director calls it a cautionary tale: "There are lots of similarities with present-day China. Shanghai today, like sixty years ago, is very materialistic. People are money-obsessed, are losing their morality. So the film, as well as a period piece, is a warning or critique for present society." (5) Shanghai Triad has also been seen as a veiled criticism of the Chinese government, the oppressive rule of iron-fisted authority, a theme which has cropped up time and again in Zhang's oeuvre.

In any event, Shanghai Triad is less a story about underworld intrigue than an exposition of ordinary people trapped in the machinery of evil. In two contrasting halves, the first part of the film is set in the brightly-lit, luxurious interiors of 1930s Shanghai while the second part takes place in the simplicity of a rural island landscape often shot in the muted light of dawn or dusk. The events of the film occur over a span of seven days.

First day: Shuisheng is summoned from the countryside by his Sixth Uncle (Li Xuejian), an underling of one of the most powerful gang leaders in Shanghai, to serve the Boss' mistress Xiao Jinbao (Gong Li) who is also the chanteuse in his nightclub.

The impact of Shanghai Triad is derived from the brilliant use of mise-en-scène, especially image contrast and camera techniques, and from its setting and atmosphere rather than from the storyline. In the first scene, the viewer, like Shuisheng, experiences the bustling confusion of a strange city as faceless bodies scurry around him at the harbour front. From broad daylight, Shuisheng is thrust into the shady environment of gang business and violence. He is taken to a large and deserted basement illuminated only by shafts of light streaming through the cracks in the room. Nobody speaks, only hand signals are used while the men 
wordlessly unload the goods from the lorry. From somewhere, the sound of cabaret singing is faintly heard. When Shuisheng attempts to help in unloading the crates, his uncle barks at him to stay away. Opium packs are being delivered to another party.

The Boss' right-hand man Song arrives with his men, presumably to supervise the deal. Since the viewer can only see the events from Shuisheng's deficient perspective, we, like him, are distanced from the action. In the silence, the viewer sees only the shadowy basement, framed in a static shot, then Song's black car standing ominously outside the doorway. Shuisheng looks around, turning his face so that his ear is toward the camera. Suddenly, gunshots resound from somewhere upstairs, birds flutter in protest and a piece of furniture is heard crashing down the steps. Shuisheng manages only to see a crumbling body and Song wiping his gun before leaving with his men. Sixth Uncle gives no explanation of the preceding events, but gravely exhorts his nephew to do as he is told. Although little has been said during this incident, the audience realises, even if Shuisheng does not, that he has been drawn into the dangerous world of mafia activities, one in which there may be no way out.

Second and third day: at the nightclub Xiao Jinbao is prevented from singing a song that the Boss particularly dislikes. That night, Shuisheng glimpses Song leaving the house as Xiao Jinbao rages in a tantrum. Shuisheng discovers that many of the Boss' servants, including Sixth Uncle, have been massacred by the Boss' rival, Fat Yu.

It is in the luminous interior of the Boss' nightclub where the most evocative and memorable scenes take place. The viewer is first introduced to the glamorous nightlife of Shanghai when Sixth Uncle brings Shuisheng to the club before presenting him to the Boss' mistress. Inside, the smoky hall invokes a dream-like vision of glamour and wealth sustained by the sight of a cosmopolitan crowd blissfully dancing and dining in their finery. Like a participant on the dance-floor, the camera glides gracefully through the room revealing the animated assembly.

Soon the band strikes up, and Xiao Jinbao takes centrestage accompanied by a chorus line. Garbed in western-style feathered headdresses and revealing costumes, the dancers daintily shuffle and sway to their leader's coquettish rendition of the song "Pretending." This is an amusing and charming moment especially for viewers acquainted with the more sober roles of Gong $\mathrm{Li}$ in the director's previous films. On another occasion, Xiao Jinbao, dressed in traditional cheongsam, sings "Moonlight", the lyrics of the romantic ballad reflecting her carefree love affair with Song, the Boss' right-hand man. This is the song the Boss detests; when he suddenly arrives at the club with his rival Fat Yu, Xiao Jinbao's performance is interrupted and she is told to entertain them with the Boss' favourite number called "Pretending."

As Fat Yu says of Xiao Jinbao, the actress Gong Li looks better than she sings, but fortunately her immense screen presence more than makes up for her vocal talent. Happily too, her somewhat contrived stage performance is perfectly in tune with her role in Shanghai Triad. Throughout the film, Xiao Jinbao uses her play-acting skills to manipulate whomever she wishes to punish or impress. Only the Boss can beat her at this game.

After Xiao Jinbao's performance, Sixth Uncle and Shuisheng go to the latter's dressing room where they witness her despotic treatment of a maid. Gong Li does a magnificent characterisation of a gang leader's moll. Benevolent and cruel, beautiful and crude, her Xiao Jinbao appears to be the female embodiment of the Boss' authority. Sixth Uncle is undoubtedly aware of this as his attitude towards her is unmistakably servile. Handing Shuisheng her lighter, Xiao Jinbao orders him to light her cigarette. The poor boy can only display his complete naivety as he looks with curiousity at the object in his hands. Sixth Uncle hurries over to help the Boss' mistress with a lit match but she takes no notice of him, merely looking on disdainfully as his fingers get burnt.

Despite the apparent contrast between Shuisheng's innocence and Xiao Jinbao's worldliness, they have the same history of being lured from the countryside to the city and they share the same plight of being trapped in the grip of a powerful gang. Says the filmmaker: "The woman and boy are doomed to fail because they cannot escape the control of the gang. These gangs were very powerful in the 1930s and much more important than just part of the criminal underworld. They were involved in politics and the economy; even Chiang Kai-shek, the Nationalist leader, was a member of one of them." ${ }^{(6)}$ In fact the Boss, admirably played by 
veteran actor Li Baotian, bears a striking resemblance to the generalissimo, though the Boss' dark glasses give him a sinister air.

Even in the underworld, personal and business relationships are carefully regulated by an outward form of order and there is constant reference to rules and the penalties for breaking them. In a scene inside the luxurious mansion, a phone call from Fat Yu reveals the exterior politeness and camaraderie that the Boss affects for his rival. While it is clear to both sides that they are enemies, protocol demands that they treat each other respectfully, at least on the surface. Having found out that Song has killed one of Fat Yu's men, the Boss decides to visit his rival "to give him face."

Before the Boss leaves, he is greeted by Xiao Jinbao; this moment seemingly confirms the force of the latter's charm over the gang leader. Xiao Jinbao is confident of her own power over the Boss, evident in the tantrum she throws after having broken up with Song. Shuisheng hears her raging at her absent lover that it is she who is the real Boss of Shanghai. Peeping through the half-opened bedroom door, the boy now sees another side to his proud mistress; surrounded by broken furniture, dishevelled, unhappy and alone.

Appropriately, the last song Xiao Jinbao performs onstage is a melancholic piece telling her lover to leave, this time attired in a Marlene Dietrich Blue Angel-style costume complete with top hat and tails. That day, while waiting in attendance outside his mistress' bedroom, Shuisheng hears the sound of gunshots in the house. Going downstairs to investigate, he sees the frantic shadows of men outside the house against the background of screeching tires. As one film critic puts it, "The massacre of the servants orchestrated by Fat $\mathrm{Yu}$ is seen as shadow-play ${ }^{(7)}$." Using a hand-held camera, the director merges the viewer's perspective with that of Shuisheng as he wanders confusedly through the corridors. Seeing a bloodied knife, he picks it up in a daze and the viewer is reminded of Xiao Jinbao's irritated query earlier about a red dress and if he had ever seen blood.

Red is a colour that prevails in most of Zhang Yimou's films. It is also the prominent colour of Shanghai Triad in the first half of the film, seen mostly on Xiao Jinbao in her costumes and make-up, signifying life and passion. But red is also the colour of death, and although the enactment of violence is never explicit in the film, references to its consequences are recurrent. Shuisheng follows a trail of blood and finds his uncle among the dead. Photographed with a red filter, the room in which Shuisheng had once taken a bath with his uncle is now a nightmarish scene filled with dead bodies submerged in blood and smoke.

Fourth to seventh day: Shuisheng flees with Xiao Jinbao and the Boss to a distant island inhabited only by a widow called Cuihua and her daughter Ah Jiao. The Boss warns that anyone leaving or landing on the island without permission will be killed.

In the second half of the film, the island landscape with its swaying reeds and picturesque sunsets offers a stark contrast to the glitter of the city. The muted greens and yellows of the lyrical setting, often seen at dusk or dawn, are endowed with a sober quality. Here where one might expect some respite from violence, the plans for the destruction of lives are methodically being carried out.

It is on this peaceful island that the depth of deception comes to light. Bored with having nothing to do, Xiao Jinbao goes to see the widow Cuihua and finds her in the middle of a romantic tryst. Shooing the inquisitive Shuisheng away from the scene, Xiao Jinbao decides to have some fun at the couple's expense and makes her way into the house on the pretext of borrowing some clothes. The play-acting begins innocently enough but it triggers a tragic chain of events.

The next day, wearing the rustic clothes of Cuihua, Xiao Jinbao engages in a singing session with Shuisheng and Ah Jiao by the dock. In this scene, Xiao Jinbao shows genuine pleasure in being with the children, revealing, for the first time, a sympathetic nature beneath her harsh exterior.

The film's Chinese title is taken from the first line of the children's lullaby that the trio sings. Like a sad refrain, the melody punctuates the film and the use of it in the film title is an ironic reminder of innocence in a corrupt world. While singing with the children, Xiao Jinbao discovers the corpse of Cuihua's lover floating in the reeds. It is only after this incident that she realizes the utter ruthlessness of the gang leader in securing his power. When she confronts the Boss with this matter, he blames her for telling him about the widow's lover and reminds her of his rules. Like her row with Song, Xiao Jinbao's quarrel with the Boss is never 


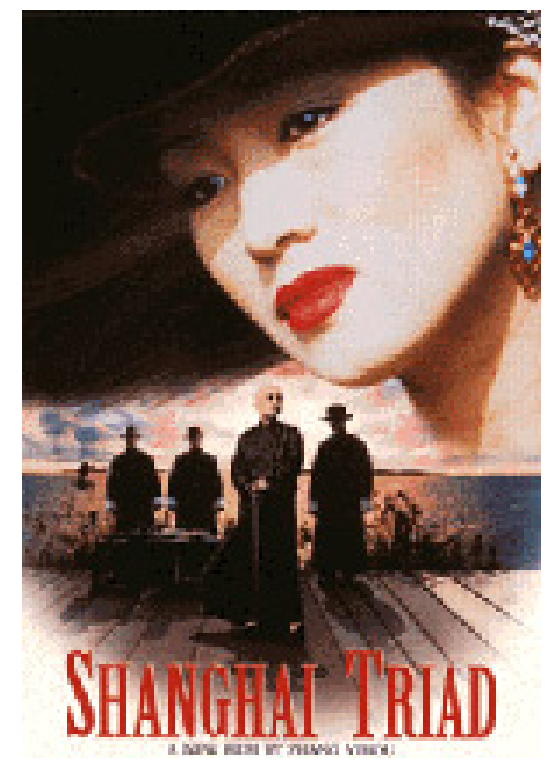

Figure 1: Shanghai Triad (publicity poster)

shown but only heard. Finally, she storms out of the room, brushing against the wind chimes. Throughout the film, the sound of bells, clocks, chimes and even coins are subtle warnings of foreboding. That evening Xiao Jinbao reveals to Shuisheng that she is, like him, a country bumpkin. Giving him some coins, she warns him against staying in the city for the money. In this scene, we sense her humanity and regret for being caught in the situation she is in.

In the film's dramatic climax, the extent of the Boss' cunning and deception is revealed to all. Overhearing a plot by Song to murder his Xiao Jinbao, Shuisheng dashes into the house to warn his mistress, only to find her playing mahjong with Song, the Boss and other members of the gang. In what is the Boss' hour of triumph, he calmly unveils the fact that Song is working for his rival Fat Yu, and that he is fully aware of Song's plot to kill him, the Boss. Moreover, he has known all along about the affair between that Song and Xiao Jinbao He has carefully set up this trap on the island for Song. As if to prove his complete mastery of the recent events, the Boss invites them to see his stomach wounds sustained from the day of massacre. Slowly getting up like someone in pain, the Boss unbuttons his shirt, exposing his stomach wrapped in bandages. With an unexpected blow at his own stomach, he proclaims the lack of a single wound there. It has all been an act. As for Song and Xiao Jinbao, they are to be executed.

The setting of a death scene in the rain is a common dramatic device reflecting the pathos of those who have been condemned. In this film, the execution scene is quite unsentimental. Song receives the penalty of being buried alive after reminding the Boss of the possibility of other informers among his trusted allies, thus raising the constant spectre of mutual suspicion among gang members. As for Xiao Jinbao, she is defiant to the end, expressing only her sorrow for those whom she has unwittingly. Her request that Cuihua and Ah Jiao be spared come too late, for Cuihua is already dead. However, Ah Jiao is to be groomed to replace Xiao Jinbao. The next morning, the Boss leaves with Shuisheng and Ah Jiao on a boat to Shanghai. Shuisheng is tied upside down to the mast.

The concluding image of the film again presents the world as it appears to Shuisheng: flat, vacillating, and topsy turvy. Illusion and reality now seem one and the same thing. Hanging upside down, Shuisheng is completely in the power of the Boss. Xiao Jinbao's warning is lost to him like the coins slipping out of his pocket into the river. The Boss tells Ah Jiao that Shuisheng, like dogs, need to be trained. When Ah Jiao announces that she would like to be just like the beautiful Xiao Jinbao, adorned with ornaments and pretty dresses, the whole cycle of greed and deception seems to begin anew.

Shanghai Triad is an unorthodox gangster film which leaves aside the depiction of blood and gore to examine 
the destructive effects of corruption on ordinary human beings. Shuisheng and Xiao Jinbao are minor players in a world where deception is a deadly game in which only the most ruthless will survive. Drawn into it through a false hope of riches, there is no chance of leaving it unscathed. By consistently employing an elliptical approach in this bleak yet beautiful film, the director has not only broken the genre's formula but has also enriched its conventions.

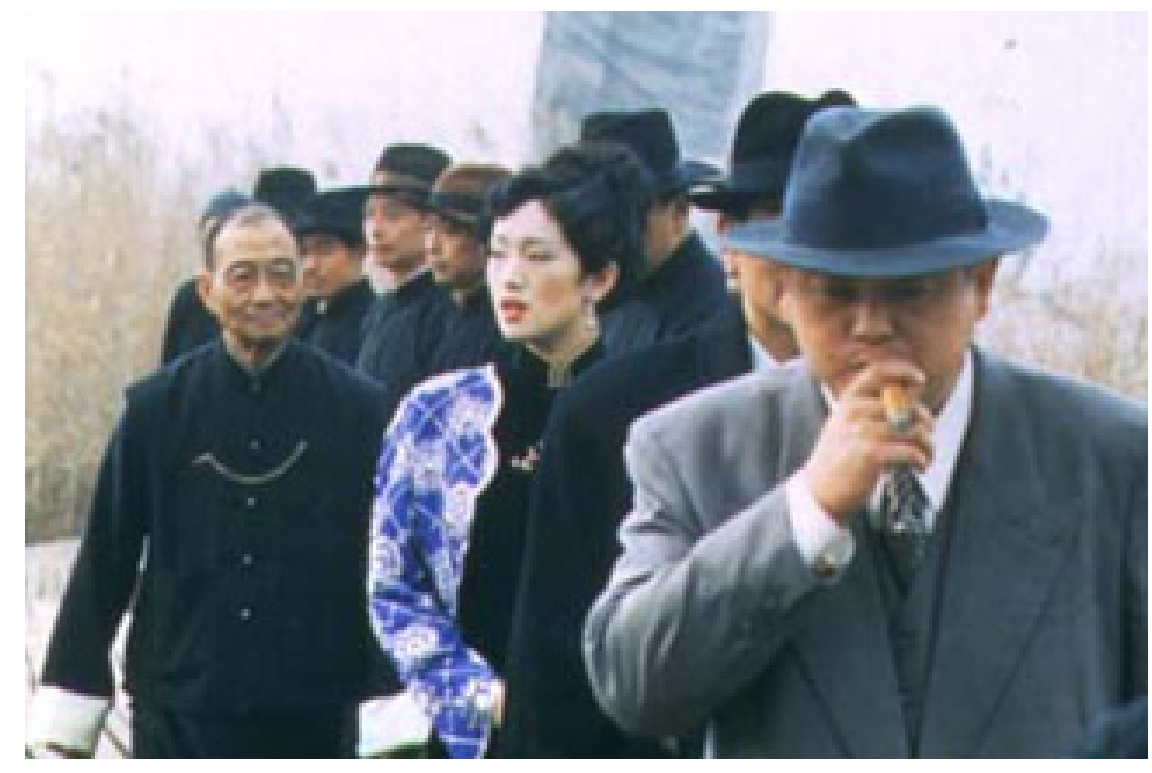

Figure 2: Shanghai Triad: To the Island

\section{Literature}

- Andrews, Nigel. "Behind Chinese Walls." Financial Times 18 November 1995, Arts, p. XVII.

- Berry, Chris, ed. Perspectives on Chinese Cinema. London: British Film Institute, 1991.

- Chen Kaige, Tony Rayns. King of the Children 83 The New Chinese Cinema. London: Faber \& Faber, 1989.

- Cook, David A. A History of Narrative Film, 2nd ed. New York: W. W. Norton \& Co., 1990.

- Kraicer, Shelly. "Allegory and Ambiguity in Zhang Yimou's Shanghai Triad." Cineaction No. 42, Spring 1997, p.15.

- Niogret, Hubert. "Yao a yao yao dao wai pe [sic!] qiao." Positif No. 413-414, July-August 1995, p. 105.

\section{Notes}

1. Red Sorghum (1987); Operation Cougar (1989); Ju Dou (1990); Raise the Red Lantern (1991); The Story of Qiu Ju (1992); To Live (1993). 2. Nigel Andrews, "Behind Chinese Walls: Nigel Andrews talks to film director Zhang Yimou about his latest movie." The Financial Times, 18 November 1995, Arts, p. XVII. 3. Zhang Yimou became famous as the cinematographer of Chen Kaige's The Yellow Earth (1984). 4. Lizzie Franke, "Shanghai Triad," Sight and Sound 5, No. 11, p. 50. 5. Andrews, "Behind Chinese Walls". 6. Ibid. 7. Franke, "Shanghai Triad." 


\section{Author Information}

Yvonne NG is the co-author of Latent Images: Film in Singapore Second edition (NUS Press, 2010); Latent Images: Film in Singapore (OUP, 2000) and Latent Images: Film in Singapore CD-ROM (Singapore, 2003). She has written on Singapore and Asian cinema and contributes to the International Film Guide. 